\title{
Experimental Investigation of Gas Evolution in Electrochemical Discharge Machining Process
}

\author{
Weidong Tang, Xiaoming Kang*, Wansheng Zhao
}

School of Mechanical Engineering, State Key Laboratory of Mechanical System and Vibration, Shanghai Jiao Tong University, Shanghai, 200240, China

*E-mail: xmkang@sjtu.edu.cn

doi: $10.20964 / 2019.01 .68$

Received: 2 August 2018 / Accepted: 12 November 2018 / Published: 30 November 2018

Electrochemical discharge machining $(E C D M)$ is a non-traditional processing technology used to machine non-conductive materials, such as glass and ceramics, based on electrochemical discharge phenomena around the tool electrode. The gas film is crucial in both discharge generation and machining processes. However, the characteristics of the gas film are not yet completely understood. The gas film evolution mechanisms and relationships between the gas film status and current signals need to be further investigated. In this study, a high-speed imaging technology was employed to investigate the evolution process of the gas film around the tool electrode. In addition, effects of current pulses on the gas film status were investigated. Experimental results showed that a large bubble was generated around the electrode owing to the gas production and bubble coalescence before the formation of a complete gas film. Observations of effects of current pulses on the gas film indicate that the current pulses with peak values larger than $1 \mathrm{~A}$ during the discharge stage were the electrolysis currents. When the applied power was turned off, the initial breakage of the gas film was observed at the bottom, which then moved upwards with an average speed of $1.03 \mathrm{~m} / \mathrm{s}$.

Keywords: Electrochemical discharge; Gas film; Bubble; Current signal; High-speed imaging

\section{$\underline{\text { FULL TEXT }}$}

(C) 2019 The Authors. Published by ESG (www.electrochemsci.org). This article is an open access article distributed under the terms and conditions of the Creative Commons Attribution license (http://creativecommons.org/licenses/by/4.0/). 